\title{
Postmenopausal endometrial carcinoma presenting as urinary incontinence: a case report
}

\author{
Priti Agrawal $^{1 *}$, Rishi Agrawal ${ }^{2}$, Jaswant Jain ${ }^{3}$, Anandi Lobo ${ }^{4}$
}

\begin{abstract}
${ }^{1}$ Department of Obstetrics, Gynecology and Infertility, Aarogya Hospital and Test Tube Baby Center, Raipur, India ${ }^{2}$ Department of General and Laparoscopic Surgery, Aarogya Hospital and Test Tube Baby Center, Raipur, India ${ }^{3}$ Department of General Surgery, Raipur Institute of Medical Sciences, Raipur, India

${ }^{4}$ Department of Pathology, Aarogya Hospital and Test Tube Baby Center, Raipur, India
\end{abstract}

Received: 24 March 2021

Accepted: 29 April 2021

\author{
*Correspondence: \\ Dr. Priti Agrawal, \\ E-mail: drpritiagrawal15@gmail.com
}

Copyright: () the author(s), publisher and licensee Medip Academy. This is an open-access article distributed under the terms of the Creative Commons Attribution Non-Commercial License, which permits unrestricted non-commercial use, distribution, and reproduction in any medium, provided the original work is properly cited.

\begin{abstract}
Endometrial carcinoma (EC) most commonly presents with postmenopausal bleeding (PMB) or blood tinged vaginal discharge. Watery vaginal discharge is usually reported in fallopian tube malignancy. We reported a case of EC where she had profuse watery discharge from private part mimicking urine and so patient visited urologist for urinary incontinence and was later diagnosed as endometroid adenocarcinoma. A 73 year old female presented with history of passing urine involuntarily for last 3 months. Endometrial biopsy revealed endometrial endometroid adenocarcinomaFIGO grade-2. FDG PET-CT scan revealed primary neoplastic pathology of uterus or endometrium with no lymphadenopathy. PMB or vaginal discharge in women with high risk factors like obesity, diabetes mellitus, unopposed oestrogen exposure needs prompt evaluation. PMB is highly suspicious of malignancy arising from cervix or uterus but copious watery discharge should also be evaluated thoroughly with ultrasound and confirmation of underlying malignancy with hysteroscopic guided endometrial sampling should be done.
\end{abstract}

Keywords: Postmenopausal bleeding, Endometrial carcinoma, Hydrometra, Gynecological malignancy

\section{INTRODUCTION}

The burden of gynaecological cancers has increased in India contributing to about $30 \%$ of total cancers among women. It is estimated that around 182,602 women by the year 2020 will be suffering from cancer of uterine cervix followed by ovary and corpus uteri. In Europe, the age standardised incidence of EC is 13.6 per 1,00,000 women with cumulative risk of $1.1 \%$, whereas in India it is $4-3$ per $1,00,000{ }^{1} 70 \%$ of these malignancies are diagnosed at an early stage with localised disease confined to uterus and have a favourable 5 year overall survival of $95 \% .^{2}$

EC most commonly presents with PMB or blood tinged vaginal discharge. ${ }^{3}$ Watery vaginal discharge is usually reported in fallopian tube malignancy. We reported a case of EC where she had profuse watery discharge from private parts mimicking urine and so patient visited urologist for urinary incontinence and was later diagnosed as endometroid adenocarcinoma.

\section{CASE REPORT}

A 73 year old female presented with history of passing urine involuntarily for last 3 months. She was gravida 4, para-4, with all normal vaginal deliveries. Last child birth was 47 years back. She had menarche at the age of 13 years and natural menopause at the age 52 years. She was having poorly controlled diabetes mellitus for last 47 years and was taking insulin therapy for past 25 years. She had hypertension, well controlled with antihypertensives for past 12 years. She had undergone appendicectomy and removal of right tubo ovarian mass 
35 years back. She had been suffering with chronic abdominal pain after this operation. Her weight was 67 $\mathrm{kg}$ and her BMI was $30.58 \mathrm{~kg} / \mathrm{m}^{2}$. Her chief complaints were passing urine involuntarily for last 3 months. Initially she was using sanitary napkins, 8-10 pads per day, but in last one month she has to use adult diapers as she was passing 3 to 5 litres of urine per day and initially visited urologist for incontinence. Patient had recurrent vaginitis for which she was using vaginal pessaries. There was no family history of colon or breast cancer. No abnormal vaginal bleeding was ever noticed. Patient also pointed that her diapers never had urinary smell. Also, she uses to pass urine normally in toilet. She was unable to sleep for last 15 days because of her wet diapers which needed frequent changing.

Upon presentation magnetic resonance imaging (MRI) showed a heterogenous lesion occupying the endometrial cavity with loss of endomyometrial interface in the fundal region and marked thinning of outer as well as inner myometrium. No obvious adjacent invasion was seen (Figure 1A). There was also heterogenous collection seen within the endometrial cavity with areas of polypoidal thickening (Figure 1B). Posterior wall fibroid of $42 \times 27$ $\mathrm{mm}$ was also seen (Figure 1C). Parametrium appeared normal with no obvious enlarged lymph nodes (Figure 1D).

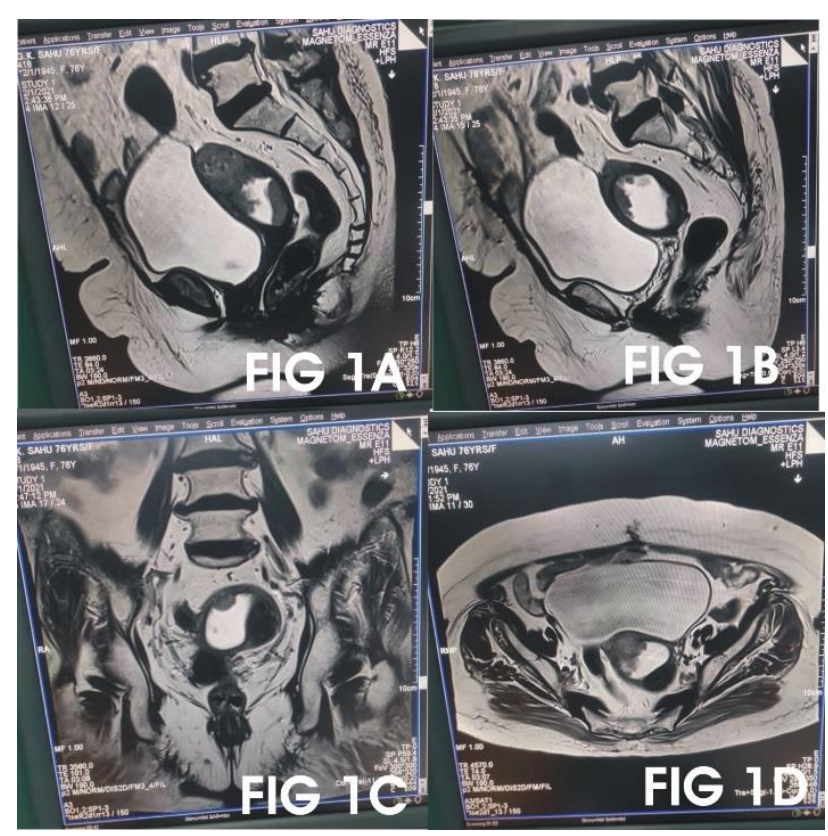

Figure 1: (A) Heterogeneous lesion occupying the entire endometrial cavity; (B) heterogeneous

collection seen within the endometrial cavity with areas of polypoidal thickening; (C) fibroid is seen; (D) no obvious enlarged nodes seen in adjacent pelvic region with normal parametrium.

Her transabdominal sonography revealed hydrometra, endometrial thickening and increased vasculature of myometrium \& endometrium (Figure 2A). Endometrial biopsy revealed endometrial endometroid
adenocarcinoma-FIGO grade-2. FDG PET-CT scan revealed primary neoplastic pathology of uterus or endometrium with no lymphadenopathy. Complete surgical staging including total hysterectomy, left salpingo oophorectomy bilateral pelvic lymph node dissection and para-aortic lymph node dissection was done (Figure 2B). Peritoneal fluid was collected for study which was negative for malignancy. Gross examination of specimen showed papillary lesions in the endometrium (Figure 2C).

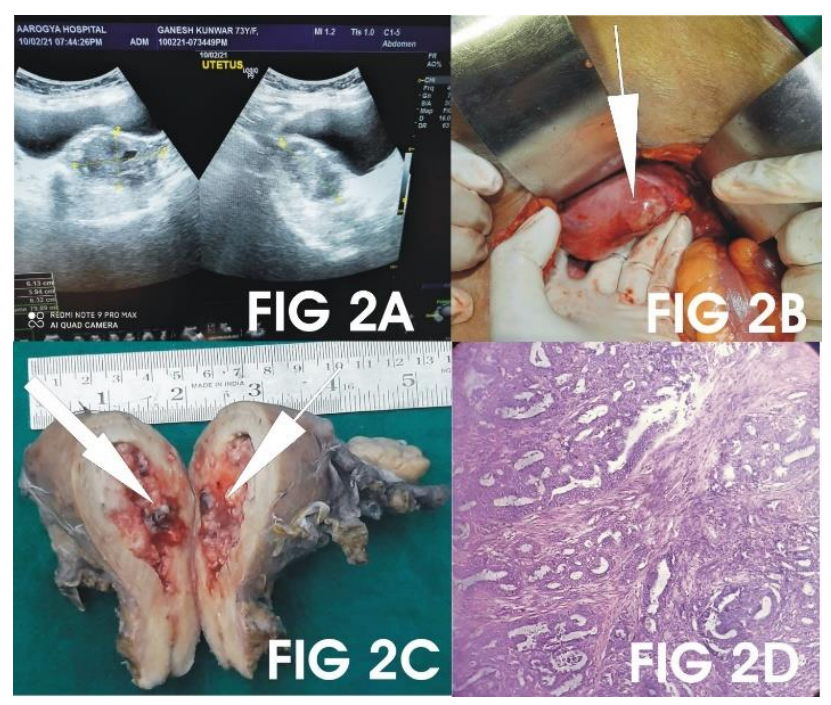

Figure 2: (A) Ultrasonography showing thickened endometrium with fluid collection; (B) intraoperative view showing marked thinning of myometrium near right cornua; (C) specimen showing papillary lesions filling the endometrial cavity; (D) microscopic image showing infiltrating confluent back to back glands in complex papillary or villoglandular arrangement.

Histopathology report suggested endometroid adenocarcinoma-FIGO grade 2 , invading more than half of the myometrium and serosa but not penetrating the serosa. The tumour extended up to lower uterine segment with lymph vascular emboli and perineural invasion. Pelvic lymph nodes ( 7 nodes from right and 10 from left) and paraaortic lymph nodes (5 nodes) were free of tumour deposits (Figure 2D). Cervix and paravaginal cuff were free of tumour deposits. Postoperative recovery of patient was uneventful.

\section{DISCUSSION}

PMB occurs in about $1-10 \%$ of women having gynaecologic malignancies and incidence decreases with time from menopause. ${ }^{4,5}$ The median age of patients at the diagnosis of EC is 63 years. There are 12 cases per $1,00,000$ women at age of 40 years and 84 per 1,00,000 at 60 years. Our patient presented with copious watery discharge which was colourless and odourless. Similar case has been reported in Taiwan but this female was having regular menses with BMI of $19.4 \mathrm{~kg} / \mathrm{m}^{2}$ with positive family history of colon cancer. ${ }^{6} \mathrm{PMB}$ or vaginal 
discharge in women with high risk factors like obesity, diabetes mellitus, unopposed oestrogen exposure needs prompt evaluation. $75 \%$ of women with EC are postmenopausal.

Ultrasonography and MRI suggested EC in our case due to thickened endometrium of greater than $11 \mathrm{~mm}$ and intracavitary fluid collection. ${ }^{7}$ The presence of intracavitary fluid in asymptomatic post-menopausal women may indicate underlying EC in about 5.4\% patients. Further we did fractional dilatation and curettage under anaesthesia. We did not do hysteroscopy as myometrium thinning was reported in fundal area and distension of cavity could have led to uterine perforation. Hysteroscopy guided endometrial sampling has a specificity of $98-100 \%$ and is superior to blind fractional curettage. ${ }^{8}$ PET-CT scan is an accurate method for the presurgical evaluation of pelvic node metastasis. The sensitivity \& specificity of FDG-PET were $60 \%$ and $98 \%$ respectively.

Preoperative pathological conformation is crucial for deciding the type of surgery. Endometrial sampling should be done in all indicated causes in order to avoid uterine morcellation which can lead to spread to malignancy beyond uterus and make assessment of myometrial invasion extremely difficult; prevent the discovery of an unexpected malignancy after inadequate surgery further requiring completion surgery.,

Mandatory workup in PMB or vaginal discharge must include family history, general comorbidity and geriatric assessment, clinical examination including pelvic examination, ultrasonography and complete pathology assessment of an endometrial biopsy or curettage specimen.

Primary fallopian tube carcinomas should also be considered especially in females presenting with profuse watery vaginal discharge. ${ }^{10}$

\section{CONCLUSION}

PMB is highly suspicious of malignancy arising from cervix or uterus but copious watery discharge should also be evaluated thoroughly with ultrasound and confirmation of underlying malignancy with hysteroscopic guided endometrial sampling should be done.
Funding: No funding sources

Conflict of interest: None declared

Ethical approval: Not required

\section{REFERENCES}

1. WHO. Fact sheet: GLOBOCAN. Estimated cancer incidence, mortality and prevalence worldwide in 2012. Available at: http://globocan.iarc.fr/Pages/fact_sheets_population. aspx. Accepted on 8 March 2021.

2. Siegel RL, Miller KD, Jemal A. Cancer statistics, 2015. CA Cancer J Clin. 2015;65(1):5-29.

3. Pakish JB, Lu KH, Sun CC, Burzawa JK, Greisinger A, Smith FA, et al. Endometrial cancer associated symptoms: a case-control study. J Wom Health. 2016;25(11):1187-92.

4. Smith PP, O'Connor S, Gupta J, Clark TJ. Recurrent postmenopausal bleeding: a prospective cohort study. J Minim Invasive Gynecol. 2014;21(5):799-803.

5. Balasubramaniam $K$, Ravin $P$, Larsen $P V$, Sondergaard J, Jarbol DE. Specific and unspecific gynecolgoical alarm symptoms-prevalance estimates in different age groups: a population-based study. Acta Obstet Gynecol Scand. 2014;94(2):191-7.

6. Ker CR, Jeng CJ. Endometrial adenocarcinoma initially mistaken as urinary incontinence. Taiwanese J Obstet Gynecol. 2020;59(4):590-3.

7. Colombo N, Creutzberg C, Amant F, Bosse T, González-Martín A, Ledermann J, et al. ESMOESGO-ESTRO consensus conference on endometrial cancer diagnosis, treatment and follow-up. Annals Oncol. 2016;27(1):16-41.

8. Hanegem NV, Prins MMC, Bongers MY, Opmeer BC, Sahota DS, Mol BWJ, et al. The accuracy of endometrial sampling in women with postmenopausal bleeding: a systematic review and meta-analysis. Eur J Obstet Gynocol Reprod Biol. 2016;197:147-55.

9. Koh W, Abu-Rustum NR, Bean S, Bradley K, Campos SM, Cho KR, et al. uterine neoplasms, version 1.2018, NCCN clinical practice guidelines in oncology. J Natl Compr Canc Netw. 2018;16(2):17099.

10. Chaudhry S, Hussain R, Zuberi MM, Zaidi Z. Rare primary fallopian tube carcinoma; a gynecologist's dilemma. J Pakistan Med Assoc. 2016;66(1):107-10.

Cite this article as: Agrawal P, Agrawal R, Jain J, Lobo A. Priti Agrawal, Rishi Agrawal, Jaswant Jain, Anandi Lobo. Int J Reprod Contracept Obstet Gynecol 2021;10:2544-6. 